\title{
Modular Synthesis of Azabicyclohexanes and Cyclobutenyl Amines
}

\author{
Kushal Dhake, ${ }^{\dagger \S}$ Kyla J. Woelk, ${ }^{\dagger \S}$ Joseph Becica $^{\dagger}$ Andy Un, ${ }^{\dagger}$ Sarah E. Jenny, ${ }^{\ddagger}$ and David C. Leitch ${ }^{\dagger *}$ \\ †Department of Chemistry, University of Victoria, 3800 Finnerty Rd., Victoria, BC V8P 5C2, Canada. \\ tDepartment of Chemistry, Temple University, 1901 N. Broad St, Philadelphia, PA 19122, United States.
}

\begin{abstract}
The development of two divergent and complementary Lewis acid catalyzed additions of bicyclobutanes to imines is described. Microscale high-throughput experimentation was integral to the discovery and optimization of both reactions. $N$-arylimines undergo formal $(3+2)$ cycloaddition with bicyclobutanes to yield azabicyclo[2.1.1] hexanes in a single step; in contrast, $N$-alkylimines undergo an addition/elimination sequence to generate cyclobutenyl methanamine products with high diastereoselectivity. These new products contain a variety of synthetic handles for further elaboration, including many functional groups relevant to pharmaceutical synthesis. The divergent reactivity observed is attributed to differences in basicity and nucleophilicity of the nitrogen atom in a common carbocation intermediate, leading to either nucleophilic attack ( $N$-aryl) or E1 elimination $(N$-alkyl).
\end{abstract}

Rigid, conformationally-restricted $\mathrm{Cs} \mathrm{p}^{3}$-based ring systems are becoming increasingly important as scaffolds and bioisosteres in small molecule drug candidates (Figure 1a). ${ }^{1-7}$ Incorporating these topologically more complex architectures often improves the drug-like properties of the resulting molecules, such as solubility, lipophilicity and metabolic stability; ${ }^{8-11}$ however, accessing many candidate structures remains difficult due to a lack of general, reliable, and modular synthetic methods. ${ }^{12-14}$ This is especially true for 2-azabicyclo[2.1.1]hexanes (aza$\mathrm{BCHs}$ ) where synthesis relies on intramolecular cyclization of prefunctionalized substrates, ${ }^{14-18}$ or stepwise functionalization of existing aza-BCHs ${ }^{19-21}$ (Figure 1b). These methods are limited with respect to modular synthesis of highly functionalized systems, which is required for medicinal chemistry SAR exploration.

As an alternative retrosynthetic concept, we postulated that aza-BCHs could be accessed via formal $(3+2)$ cycloaddition between bicyclobutanes ${ }^{22-28}$ and imines, analogous to the reactivity of donor-acceptor cyclopropanes ${ }^{29-31}$ (Figure 1b). This approach would directly generate highly substituted aza-BCHs in a modular fashion, using readily available imines and bicyclobutanes as building blocks. Here, we show that Lewis acid catalysis enables divergent reactivity between imines and bicyclobutanes, giving two classes of densely-functionalized amine products. With $\mathrm{N}$-aryl imines, the envisioned cycloaddition leads to a variety of aza-BCHs under mild conditions. In contrast, $N$-alkyl imines react diastereoselectively to give cyclobutenyl methanamines as the major product (Figure 1c). Synthesis of highly-substituted and stereochemically-defined cyclobutyl scaffolds is often challenging. ${ }^{32-34}$ This imine addition to bicyclobutanes, complementary to aza-BCH formation, gives rise to structurally complex cyclobutenes that have multiple points for further functionalization. Both of these amine product classes are potentially valuable additions to the growing set of $\mathrm{Cs} p^{3}$ rich scaffolds being investigated in medicinal chemistry. ${ }^{35}$

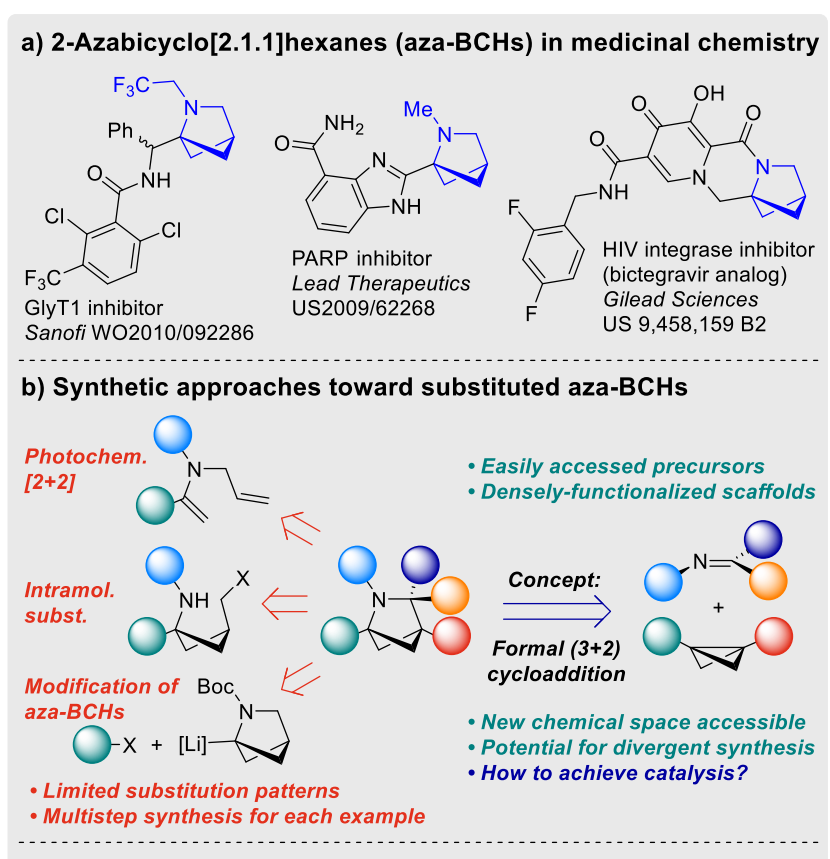

c) This work: divergent reactivity for new $\mathbf{N}$-containing scaffolds

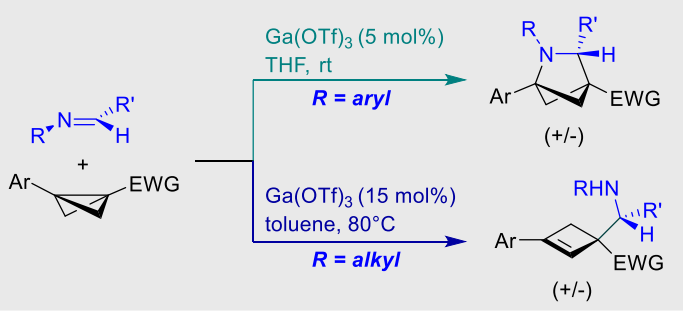

Figure 1. a) Potential of azabicyclo[2.1.1] hexanes (aza-BCHs) as structural elements in medicinal chemistry; b) synthetic challenges in existing approaches and new retrosynthetic concept; c) divergent access to azabicyclohexanes and cyclobutenyl methanamines. 
a)

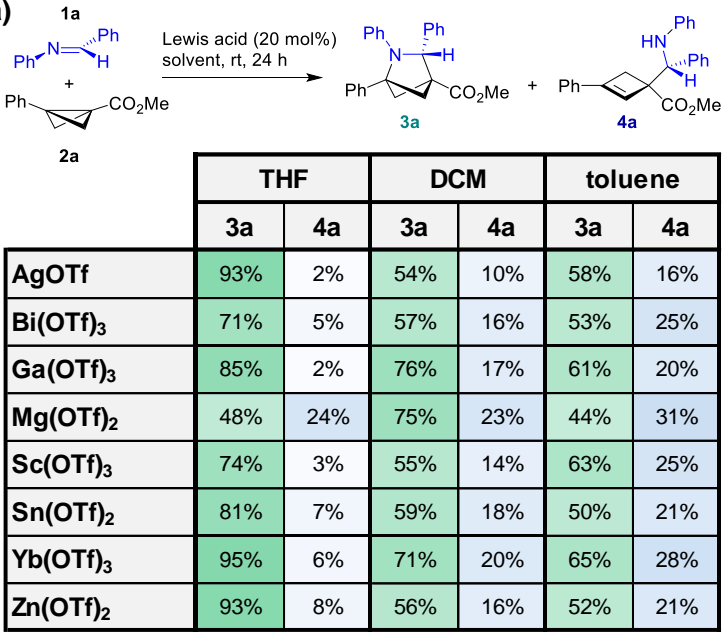

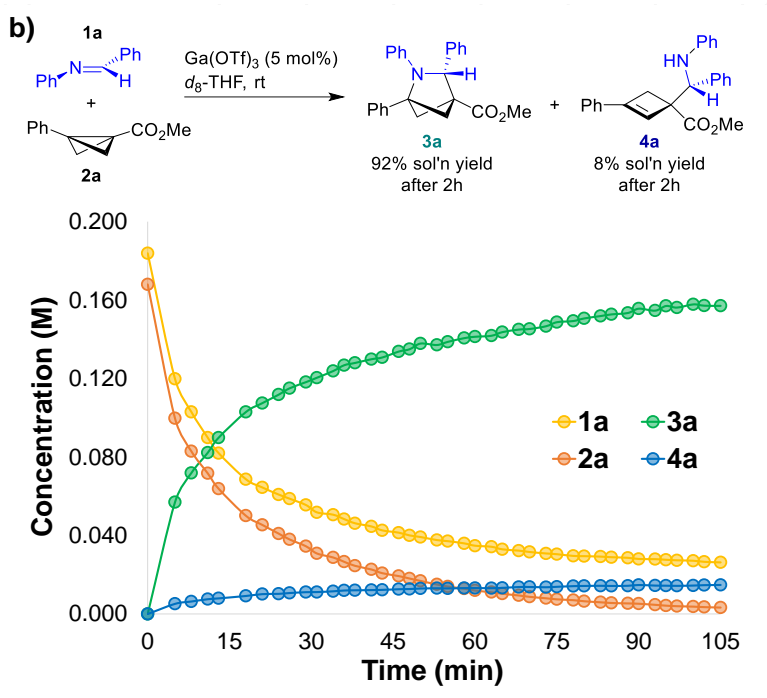

C) 1 aa

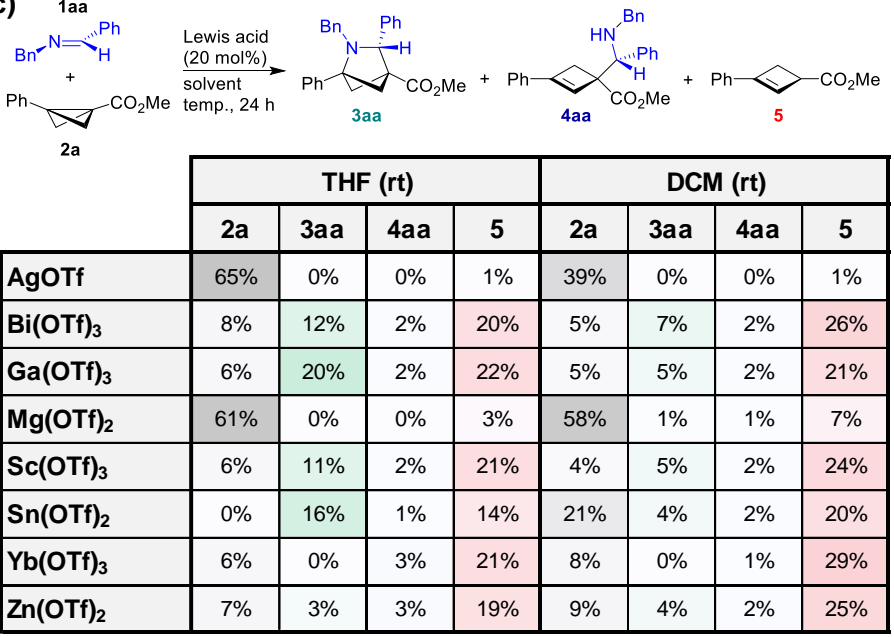

\begin{tabular}{|l|c|c|c|c|c|c|c|c|}
\cline { 2 - 10 } \multicolumn{1}{c|}{} & \multicolumn{4}{c|}{ toluene (rt) } & \multicolumn{3}{c|}{$\boldsymbol{d}_{6}$-benzene $\left(\mathbf{8 0}{ }^{\circ} \mathbf{C}\right)$} \\
\cline { 2 - 10 } \multicolumn{1}{c|}{} & 2a & 3aa & 4aa & $\mathbf{5}$ & 2a & 3aa & 4aa & $\mathbf{5}$ \\
\hline $\mathbf{A g O T f}$ & $53 \%$ & $0 \%$ & $0 \%$ & $0 \%$ & $23 \%$ & $8 \%$ & $59 \%$ & $1 \%$ \\
\hline $\mathbf{B i}(\mathbf{O T f})_{3}$ & $3 \%$ & $5 \%$ & $2 \%$ & $26 \%$ & $4 \%$ & $16 \%$ & $81 \%$ & $2 \%$ \\
\hline $\mathbf{G a}(\mathbf{O T f})_{3}$ & $67 \%$ & $5 \%$ & $4 \%$ & $38 \%$ & $4 \%$ & $12 \%$ & $83 \%$ & $2 \%$ \\
\hline $\mathbf{M g}(\mathbf{O T f})_{2}$ & $88 \%$ & $0 \%$ & $0 \%$ & $2 \%$ & $80 \%$ & $2 \%$ & $15 \%$ & $4 \%$ \\
\hline $\mathbf{S c}(\mathbf{O T f})_{3}$ & $1 \%$ & $3 \%$ & $1 \%$ & $15 \%$ & $1 \%$ & $14 \%$ & $85 \%$ & $1 \%$ \\
\hline $\mathbf{S n}(\mathbf{O T f})_{2}$ & $1 \%$ & $4 \%$ & $2 \%$ & $19 \%$ & $7 \%$ & $12 \%$ & $70 \%$ & $3 \%$ \\
\hline $\mathbf{Y b}(\mathbf{O T f})_{3}$ & $0 \%$ & $0 \%$ & $0 \%$ & $16 \%$ & $10 \%$ & $12 \%$ & $74 \%$ & $2 \%$ \\
\hline $\mathbf{Z n}(\mathbf{O T f})_{2}$ & $10 \%$ & $3 \%$ & $2 \%$ & $16 \%$ & $24 \%$ & $9 \%$ & $57 \%$ & $2 \%$ \\
\hline
\end{tabular}

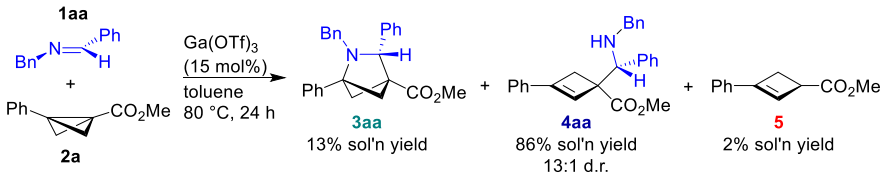

Figure 2. a) Microscale high-throughput screening results (solution yields) for the Lewis acid catalyzed addition of $N$-phenyl imine 1a to bicyclobutane 2a, revealing azabicyclohexane 3a as the major product and cyclobutenyl methanamine 4a as a minor product; b) reaction progress plot with $\mathrm{Ga}(\mathrm{OTf})_{3}(5 \mathrm{~mol} \%)$ as catalyst, indicating both products are formed in parallel pathways; c) microscale high-throughput screening results (solution yields) for the Lewis acid catalyzed addition of $N$-benzyl imine 1aa to 2a, revealing formation of cyclobutenyl methanamine $4 \mathbf{a a}$ as the major product at elevated temperature in $d_{6}$-benzene, and confirmation of product distribution using $\mathrm{Ga}(\mathrm{OTf})_{3}(15$ mol\%) in toluene at $80{ }^{\circ} \mathrm{C}$. All solution yields are obtained by ${ }^{1} \mathrm{H}$ NMR spectroscopy using 1,3,5-trimethoxybenzene as an internal standard.

Initial reaction discovery was enabled by microscale highthroughput screening using a combination of solvents and Lewis acids for the coupling of imine substrates (1a and 1aa) and bicyclobutane 2a (Figure 2). ${ }^{36,37}$ A multivariate design allowed us to evaluate all combinations between Lewis acid identity and solvent to account for possible interaction effects. ${ }^{38}$ For $\mathrm{N}$-aryl imine 1a, catalysis at room temperature forms both the desired aza-BCH $3 \mathbf{a}$ and the corresponding cyclobutenyl methanamine $4 \mathbf{a}$ (Figure 2a). The $\mathbf{3 a}$ to $\mathbf{4 a}$ ratio depends mainly on solvent, with THF giving 2-to-10-fold less 4a than DCM and toluene. Every Lewis acid screened gives similar reaction outcomes except for $\mathrm{Mg}(\mathrm{OTf})_{2}$, which gives a higher amount of $\mathbf{4 a}$ even in THF. Among the catalysts tested, AgOTf and Ga(OTf $)_{3}$ give the smallest amount of $\mathbf{4 a}$; evaluating these two catalysts at lower loading $(5 \mathrm{~mol} \%)$ revealed $\mathrm{Ga}(\mathrm{OTf})_{3}$ as superior. ${ }^{39}$

To understand the origin of the product distribution, we monitored reaction progress using in situ ${ }^{1} \mathrm{H}$ NMR spectroscopy (Figure 2b). We observe excellent mass balance for the conversion of $\mathbf{1 a} / \mathbf{2} \mathbf{a}$ into the $\mathbf{3 a} / \mathbf{4 a}$ mixture, with a constant $\mathbf{3 a} \mathbf{4} \mathbf{a}$ ratio of $11: 1$ throughout the reaction, and a $92 \%$ solution yield of $\mathbf{3 a}$ after $2 \mathrm{~h}$. This reaction profile is consistent with $\mathbf{3 a}$ and $\mathbf{4 a}$ being formed in parallel pathways that share a common intermediate.

In contrast to 1a, productive reactions of $N$-alkyl imine 1aa with $\mathbf{2 a}$ did not readily proceed at room temperature, regardless of the Lewis acid/solvent combination (Figure 2c). Instead, we observe generally poor mass-balance, and significant amounts of the cyclobutene side product $\mathbf{5}$. In select cases with THF solvent, we do observe the aza-BCH 3aa in low yield (12-20\%). In an attempt to improve the reaction outcome, we assessed an elevated temperature $\left(80{ }^{\circ} \mathrm{C}\right)$ using $d_{6}$-benzene. Under these conditions, we observe a complete reversal of chemoselectivity to give the cyclobutenyl methanamine 4aa as the major product, with $\mathrm{Ga}(\mathrm{OTf})_{3}$ again among the best catalysts. This microscale result was confirmed using $\mathrm{Ga}(\mathrm{OTf})_{3}(15 \mathrm{~mol} \%)$, giving 4 aa in $86 \%$ solution yield with a d.r. of $13: 1$. We assessed the possibility of 4aa formation by ring-opening elimination of 3aa, ${ }^{40,41,42}$ as well as $\mathbf{3 a a}$ formation by intramolecular hydroamination $^{43}$ of $\mathbf{4 a a}$ (eq. 1). Heating isolated 3aa or 4aa in the presence of $\mathrm{Ga}(\mathrm{OTf})_{3}$ led to no observable conversion, consistent with parallel reaction pathways for $\mathbf{3 a a} / \mathbf{4 a a}$ formation. 

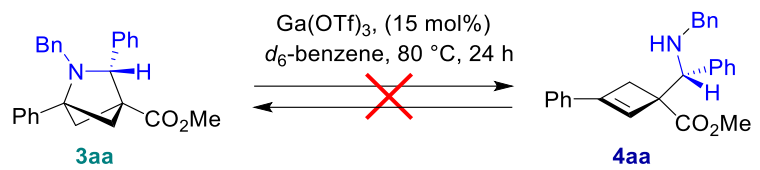

During our efforts to scale-up the synthesis of both 3a and 4aa, we initially observed small yet variable amounts of the cyclobutene $\mathbf{5}$ as a side product. To elucidate the factors that contribute to its formation, we conducted a series of control experiments on the bicyclobutane 2a (Table 1). While 2a is stable in solution ( $d_{6}$-benzene or THF) at room temperature over extended time periods, heating 2a in $d_{6}$-benzene over $24 \mathrm{~h}$ gives $67 \%$ solution yield of $\mathbf{5}$ (entry 1 ). This extent of thermal decomposition is not consistent with the observed product distribution for the formation of 4aa during catalysis under optimized conditions. In striking contrast, heating a solution of 1aa and $\mathbf{2 a}-$ a no-catalyst control experiment - leads to no observable reaction (entry 2). Mixing 2a with $\mathrm{Ga}(\mathrm{OTf})_{3}$ in $d_{6}$-benzene (entry 3 ) or THF (entry 4) leads to near immediate and complete conversion of 2a into 5. Perplexingly, addition of 1a or 1aa into the mixtures from entries 3 and 4 represents the optimized catalytic reaction conditions from Figure 2, where we observe very little (or no) 5.

Table 1. Decomposition of 2a into cyclobutene 5.

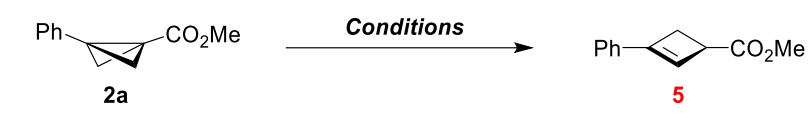

\begin{tabular}{|c|c|c|}
\hline Entry & Conditions & $\begin{array}{l}\text { Yield } \\
\mathbf{5}(\%)^{\mathrm{b}}\end{array}$ \\
\hline 1 & $d_{6}$-benzene, $80^{\circ} \mathrm{C}, 24 \mathrm{~h}$ & 67 \\
\hline 2 & 1aa (1.5 equiv) $d_{6}$-benzene, $80^{\circ} \mathrm{C}, 24 \mathrm{~h}$ & n.r. ${ }^{b}$ \\
\hline 3 & $\mathrm{Ga}(\mathrm{OTf})_{3}(15 \mathrm{~mol} \%), d_{6}$-benzene, rt, $20 \mathrm{~min}$ & $>95$ \\
\hline 4 & $\mathrm{Ga}(\mathrm{OTf})_{3}(5 \mathrm{~mol} \%)$, THF, rt, $20 \mathrm{~min}$ & $>95$ \\
\hline 5 & $\begin{array}{l}\text { 2,6-lutidine ( } 1.5 \text { equiv), } d_{6} \text {-benzene, } \\
80^{\circ} \mathrm{C}, 24 \mathrm{~h}\end{array}$ & n.r. ${ }^{b}$ \\
\hline 6 & $\begin{array}{l}\text { 2,6-lutidine ( } 1.5 \text { equiv), } \mathrm{Ga}(\mathrm{OTf})_{3}(15 \mathrm{~mol} \%) \text {, } \\
d_{6} \text {-benzene, } 80^{\circ} \mathrm{C}, 24 \mathrm{~h}\end{array}$ & n.r. ${ }^{b}$ \\
\hline 7 & $\begin{array}{l}\text { 2,6-lutidine (1.1 equiv), } \mathrm{Ga}(\mathrm{OTf})_{3}(5 \mathrm{~mol} \%) \text {, } \\
\text { THF, rt, } 24 \mathrm{~h}\end{array}$ & n.r. ${ }^{b}$ \\
\hline
\end{tabular}

${ }^{\text {aDetermined by }}{ }^{1} \mathrm{H}$ NMR spectroscopy versus internal standard (1,3,5-trimethoxybenzene). ${ }^{\text {bn.r. }}=$ no reaction $(\mathbf{5}$ not observed, $>95 \%$ 2a remaining).

These results are consistent with decomposition of $\mathbf{2 a}$ being mediated by trace Brønsted acid, and that the imine substrate quenches this acid to inhibit decomposition during catalysis. To test this hypothesis, we carried out additional control experiments similar to those from entries 1,3 , and 4 , but with the addition of 2,6-lutidine to emulate the basicity of the imine substrate (entries 5-7). In every case, no reaction occurs, leaving 2a intact. Not only do these experiments reveal the probable source of bicyclobutane-to-cyclobutene isomerization as trace acid, it also reveals a key practical aspect of reaction order-of-addition: the Lewis acid catalyst must be added last to prevent rapid bicyclobutane decomposition.

Using the two sets of reaction conditions from Figure 2, we explored the scope of aza-BCHs (Method A) and cyclobutenyl methanamines (Method B) accessible from imines and bicyclobutanes containing a variety of pharmaceutically-relevant substituents and functional groups (Figure 3). Using Method A, compound 3a is isolated in $86 \%$ yield on $1 \mathrm{mmol}$ scale. Increasing steric bulk on the imine $N$-aryl group with $o$-tolyl (3b) and 2-naphthyl (3c) substituents is compatible with the chemistry, though incorporating a 2,6-methylphenyl group at nitrogen leads to no reaction. Electron donating $(\mathbf{3 d}, \mathbf{3 e})$ and withdrawing groups $(\mathbf{3 f}, \mathbf{3 g}, \mathbf{3 h})$ on the $N$-aryl ring are also compatible, providing substituents for further functionalization.

A series of multisubstituted $N$-aryl imines are also successful, including those with electron donating and withdrawing groups on both aryl rings $(\mathbf{3 i}, \mathbf{3 j}), 5$ - and 6-membered heterocycles (3k3o), and halides (31, 3m). Particularly noteworthy is 3l, which contains $\mathrm{Ar}-\mathrm{I}$ and 2-Cl-pyridyl moieties available for further functionalization; importantly, we observe no competing reactivity at the electrophilic 2-Cl-pyridyl group. Finally, alternative aryl and electron withdrawing groups on the bicyclobutane are compatible, including $p$-F-phenyl (3p), primary (3q), secondary (3r), and tertiary (3s) alkyl esters, and morpholine amide (3t). Unfortunately, a menthyl ester provides no stereoinduction ( $\mathbf{3 r}$ is isolated with 1.4:1 d.r.). In some cases, we observe the corresponding cyclobutenyl methanamines (4) as minor products that co-elute with the aza-BCHs (3) during chromatography (3/4d, $\mathbf{k}, \mathbf{n}, \mathbf{o}$, and $\mathbf{s})$.

For $\mathrm{N}$-alkyl imine substrates, Method B gives a variety of cyclobutenyl methanamines (Figure 3, right), with the pictured diastereomer as the major product; the relative stereochemistry shown is assigned based on NMR characterization of the iodoamination products (vide infra). In all cases, we prioritized enriching the major diastereomer during purification rather than seeking maximum chemical yield. Compound 4aa is isolated in $66 \%$ yield with increased stereopurity after purification (d.r. = 27:1 versus 11:1 initially). A $p$-methoxybenzyl (PMB) group is compatible, providing an acid-labile protecting group for nitrogen (4bb). Increased steric bulk at nitrogen, including cyclohexyl and tert-butyl groups (4cc, 4dd), leads to lower yield but improved diastereoselectivity; for $\mathbf{4 c c}$, challenges with isolation by column chromatography are partly responsible for the low yield (43\% NMR yield versus $19 \%$ isolated). Several $C$-aryl groups are also compatible, including 1-naphthyl (4ee) and various heterocycles (4ff-4ii). Notably, unsubstituted 5-membered heterocycles (4ff and $\mathbf{4 g g}$ ) give decreased diastereoselectivity relative to phenyl, though the larger 1,3-dimethylpyrazolyl product (4hh) is formed in 13:1 d.r. (17:1 after purification). A 2-Cl-pyridyl group can also be incorporated (4ii).

Using $(S)$ - $\alpha$-methylbenzyl as a chiral auxiliary at nitrogen leads to only two of the four possible stereoisomers being observable by NMR, with the major stereoisomer formed with 67:1 d.r. (4jj-4ll). The absolute stereochemistry pictured is assigned based on 2D NOESY analysis of $\mathbf{6 j \mathbf { j }}$ (vide infra). We have also isolated the minor diastereomer of 4ll, confirming by 2D NOESY that it possesses the same relative stereochemistry as the major diastereomer at the two new stereogenic centers. ${ }^{39}$ In other words, the observed diastereoselectivity is controlled by the $(S)$ - $\alpha$-methylbenzyl chiral auxiliary. Finally, bicyclobutanes with alternative aryl and electron withdrawing groups are compatible (4mm-4pp); in the case of $\mathbf{4 m m}$, we observe the corresponding aza-BCH (3mm) as a co-eluting minor product. As for $\mathbf{3 r}$, a menthyl ester in $\mathbf{4 p p}$ provides effectively no stereoinduction, with two major ( $\sim 3: 2$ ratio) and two minor diastereomers observed by NMR spectroscopy. 


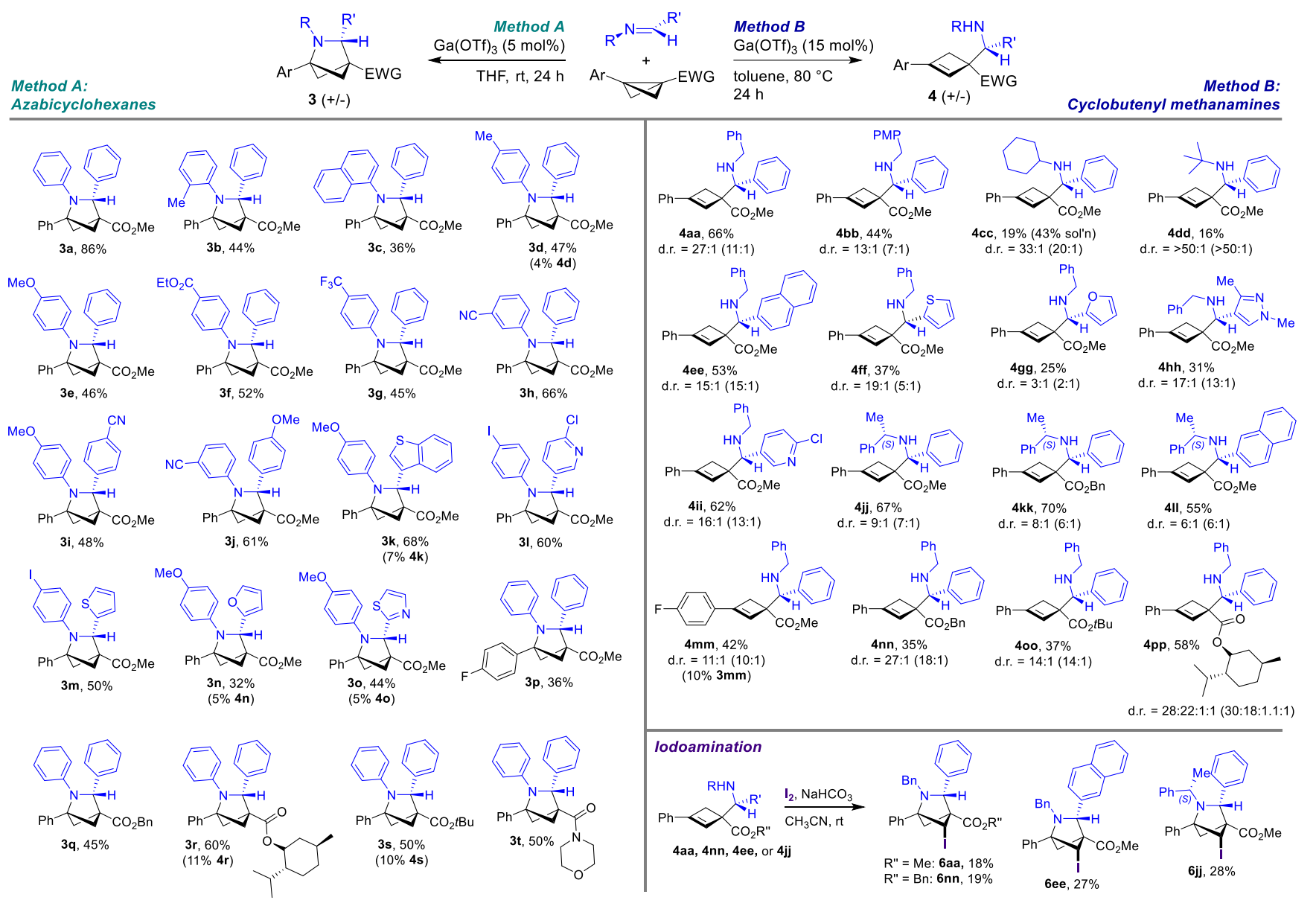

Figure 3. Scope of the divergent reactions using $N$-aryl imines (Method A) and $N$-alkyl imines (Method B); d.r. values in parentheses determined by ${ }^{1} \mathrm{H}$ NMR spectroscopy of crude products prior to purification. Selected cyclobutenyl methanamine products were converted to azabicyclohexanes via an iodoamination reaction, yielding single diastereomers with four contiguous stereocenters. The relative stereochemistry of 6aa was determined by 2D NOESY, enabling assignment of the relative stereochemistry of the cyclobutenyl methanamine products by analogy; the absolute stereochemistry of $\mathbf{6 j j}$ was similarly assigned by 2D NOESY (see Supporting Information for further details on stereochemical assignment).

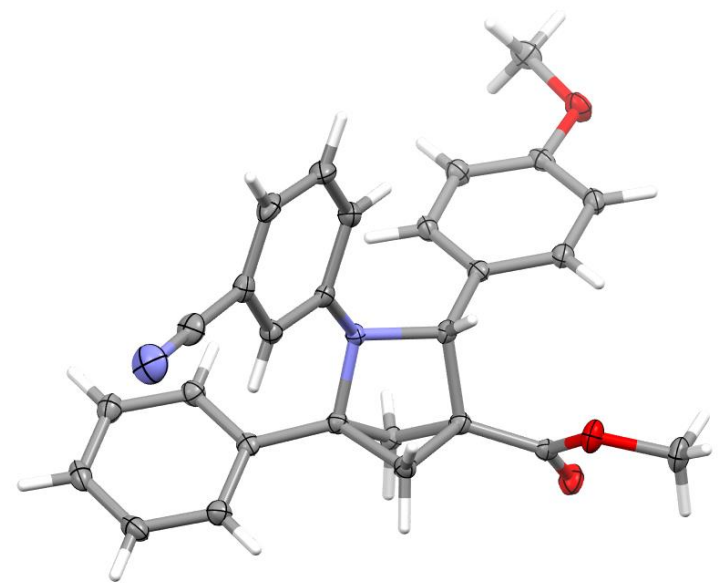

Figure 4. Solid-state molecular structure of $\mathbf{3 j}$ (ellipsoids plotted at $50 \%$ probability, enantiomer of $\mathbf{3 j}$ from extended structure not shown for clarity). See SI for metrical parameters.

To demonstrate potential synthetic applications of these cyclobutenes, and to generate conformationally rigid products for stereochemical assignment by 2D NOESY, ${ }^{39}$ we converted four cyclobutenes into aza-BCHs (6aa, 6ee, $\mathbf{6 j j}, \mathbf{6 n n})$ using a general and unoptimized iodoamination reaction. Taking advantage of iodonium formation on the opposite side of the cyclobutene to the methanamine substituent enables formation of diastereomerically pure products containing four contiguous stereocenters, two of which are tetrasubstituted. Thus, this iodoamination reaction enables access to complex $N$-alkyl aza-BCHs with several points for potential functionalization. The relative stereochemistry for 6aa was established using 2D NOESY; a correlation is observed between the methine hydrogen $\alpha$ to nitrogen and the hydrogen attached to the same carbon as the iodine, clearly indicating these two protons are on the same side of the azabicyclohexane ring. ${ }^{39}$ Using $(S)$ - $\alpha$-methylbenzyl as a chiral auxiliary gives $\mathbf{6 j j}$ with defined absolute configuration, which we also determined by 2D NOESY. Key correlations between the $\alpha$-methylbenzyl hydrogens and the hydrogens on the azabicyclohexane ring are consistent with the pictured absolute stereochemistry. ${ }^{39}$

To rationalize the divergent reaction pathways leading to aza$\mathrm{BCH}$ or cyclobutene formation, we propose the general mechanism shown in Figure 5a, which shares aspects of prior proposals for the addition of strongly electron deficient ketones or alkenes to bicyclobutane ${ }^{44}$ and 1-azabicyclobutane ${ }^{45}$ substrates. In this proposal, the initial reaction between bicyclobutane and imine proceeds through Lewis acid induced enolate formation 
at the bicyclobutane; this Lewis acid activation is consistent with the rapid isomerization of $\mathbf{1 a}$ to $\mathbf{5}$ in the absence of imine (Table 1). Subsequent $\mathrm{C}-\mathrm{C}$ bond formation between this enolate and the imine (which could also be activated by coordination to the Lewis acid) affords the carbocation species 7 . This key intermediate could then undergo either a ring-closing nucleophilic attack by nitrogen onto the carbocation, or an intramolecular E1 elimination. The relative rates of these two pathways will be controlled by the kinetic nucleophilicity versus basicity of the nitrogen atom: for $\mathrm{N}$-aryl groups, the nitrogen is more nucleophilic than basic, whereas $N$-alkyl are more basic than nucleophilic. This parallel mechanism is also consistent with the simultaneous formation of $\mathbf{3 a}$ and $\mathbf{4 a}$ (Figure 2b) and the inability for $\mathbf{3 a a}$ and $\mathbf{4 a a}$ to interconvert under the reaction conditions (eq. 1).

To explain the observed diastereoselectivity for the synthesis of cyclobutenyl methanamines (4), we propose the stereochemical model in Figure 5b. The major and minor diastereomers are differentiated by whether $\mathrm{H}_{\mathrm{a}}$ or $\mathrm{H}_{\mathrm{b}}$ undergoes elimination. Asdrawn, a clockwise $(\mathrm{CW})$ bond rotation to remove $\mathrm{H}_{\mathrm{b}}$ will lead to higher torsional strain due to the eclipsing interaction between the $C-\mathrm{R}$ ' group and the electron-withdrawing group on the cyclobutane. In contrast, a counter clockwise (CCW) bond rotation to remove $\mathrm{H}_{\mathrm{a}}$ requires less torsional strain, leading to the major observed diastereomer. Work is underway to further elucidate the operative mechanistic pathways.

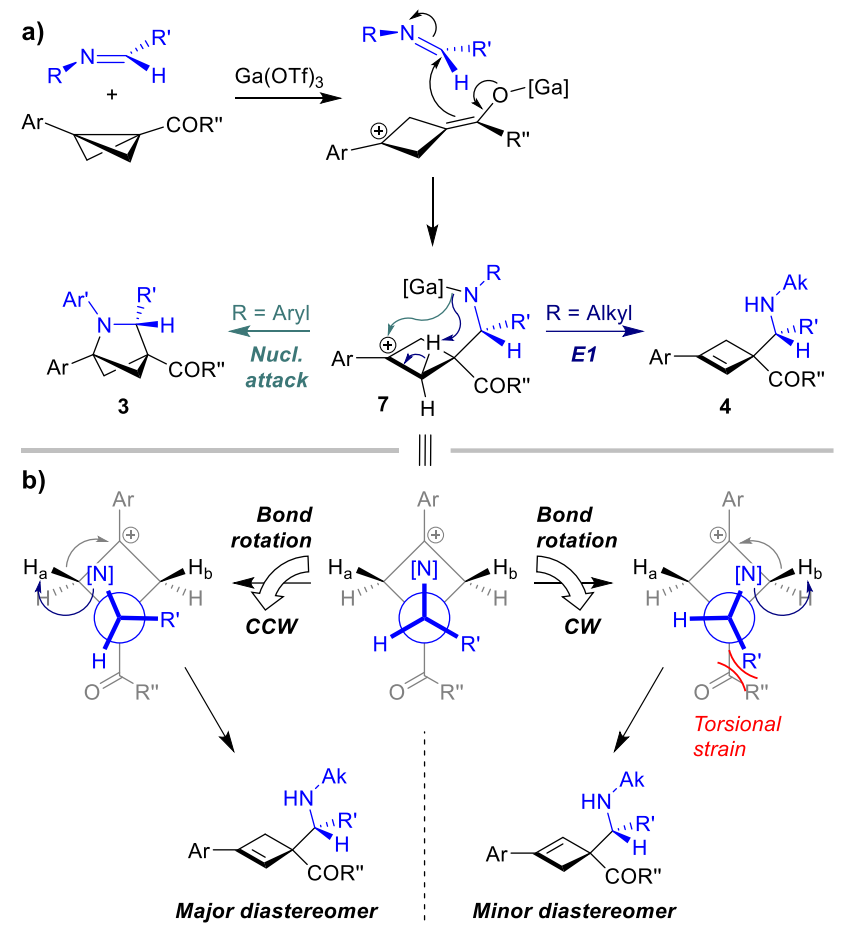

Figure 5. a) Proposed pathways for the formation of $\mathbf{3}$ and $\mathbf{4}$ from a common carbocation intermediate; b) stereochemical model for the observed relative stereochemistry in cyclobutenyl methanamine formation $(\mathrm{CW}=$ clockwise; $\mathrm{CCW}=$ counterclockwise $)$.

In summary, we have developed two complementary approaches to the functionalization of bicyclobutanes by exploiting the divergent reactivity exhibited by $N$-aryl and $N$-alkyl imines under Lewis acid catalysis. The resulting products provide a unique platform for chemical space exploration in pursuit of new, $\mathrm{Csp}^{3}$-rich drug candidates, especially given the func- tional group compatibility exhibited with respect to heterocycles and diverse synthetic handles. Work is ongoing to explore the mechanistic and synthetic features of this chemistry, and to apply these techniques toward complex molecule synthesis relevant to the discovery of active pharmaceutical ingredients.

\section{ASSOCIATED CONTENT}

Supporting Information. Detailed experimental procedures, full tables of screening data, characterization data for new compounds, and X-ray crystallography details. The CIF for 3k is deposited with the CCDC with deposition number 2103579.

\section{AUTHOR INFORMATION}

\section{Corresponding Author}

*dcleitch@uvic.ca

\section{Author Contributions}

$\S$ These authors contributed equally.

Notes

The authors declare no competing financial interest.

\section{ACKNOWLEDGMENT}

We acknowledge with respect the Lekwungen peoples, on whose traditional territory the University of Victoria (UVic) stands, and the Songhees, Esquimalt, and WSÁNEĆ peoples whose historical relationships with the land continue to this day. We thank Prof. Jeremy Wulff (UVic) and Prof. Michael Zdilla (Temple) for insightful discussions. We also thank UVic, NSERC, CFI, and BCKDF for general operating and equipment funds.

\section{REFERENCES}

(1) Mann, A. Conformational Restriction and/or Steric Hindrance in Medicinal Chemistry. In The Practice of Medicinal Chemistry; Academic Press/Elsevier: Amsterdam, 2008; p 363.

(2) Lovering, F.; Bikker, J.; Humblet, C. Escape from Flatland: Increasing Saturation as an Approach to Improving Clinical Success. J. Med. Chem. 2009, 52, 6752-6756.

(3) Lovering, F. Escape from Flatland 2: Complexity and Promiscuity. Med. Chem. Commun. 2013, 4, 515-519.

(4) Dargazanli, G.; Estenne-Bouhtou, G.; Mafroud, A.-K. N-[(2Azabicyclo[2.1.1]hex-1-yl]-aryl-methyl]-Benzamide Derivatives, Preparation Thereof, and Therapeutic Use Thereof. WO2010092286A1, August 19, 2010.

(5) Chu, D. Novel Inhibitors of Poly(Adp-Ribose)Polymerase (Parp). US20090062268A1, March 5, 2009.

(6) Desai, M. C.; Ji, M.; Jin, H.; Martin, T. A. T.; Pyun, H.-J. Substituted Pyrido[1',2':4,5]Pyrazino[1,2-a]Azepines for Treating Viral Infections. US9458159B2, October 4, 2016.

(1) Mykhailiuk, P. K. Saturated Bioisosteres of Benzene: Where to Go Next? Org. Biomol. Chem. 2019, 17, 2839-2849.

(8) Ma, X.; Sloman, D. L.; Han, Y.; Bennett, D. J. A Selective Synthesis of 2,2-Difluorobicyclo[1.1.1]Pentane Analogues: "BCPF2." Org. Lett. 2019, 21, 7199-7203.

(9) Bychek, R. M.; Hutskalova, V.; Bas, Y. P.; Zaporozhets, O. A.; Zozulya, S.; Levterov, V. V.; Mykhailiuk, P. K. Difluoro-Substituted Bicyclo[1.1.1]Pentanes for Medicinal Chemistry: Design, Synthesis, and Characterization. J. Org. Chem. 2019, 84, 15106-15117.

(10) Denisenko, A.; Garbuz, P.; Shishkina, S. V.; Voloshchuk, N. M.; Mykhailiuk, P. K. Saturated Bioisosteres of Ortho-Substituted Benzenes. Angew. Chem. Int. Ed. 2020, 59, 20515-20521.

(11) Levterov, V. V.; Panasyuk, Y.; Pivnytska, V. O.; Mykhailiuk, P. K. Water-Soluble Non-Classical Benzene Mimetics. Angew. Chem. Int. Ed. 2020, 59, 7161-7167. 
(12) Gianatassio, R.; Lopchuk, J. M.; Wang, J.; Pan, C.-M.; Malins, L. R.; Prieto, L.; Brandt, T. A.; Collins, M. R.; Gallego, G. M.; Sach, N. W.; Spangler, J. E.; Zhu, H.; Zhu, J.; Baran, P. S. Strain-Release Amination. Science 2016, 351, 241-246.

(13) Lopchuk, J. M.; Fjelbye, K.; Kawamata, Y.; Malins, L. R.; Pan, C.-M.; Gianatassio, R.; Wang, J.; Prieto, L.; Bradow, J.; Brandt, T. A.; Collins, M. R.; Elleraas, J.; Ewanicki, J.; Farrell, W.; Fadeyi, O. O.; Gallego, G. M.; Mousseau, J. J.; Oliver, R.; Sach, N. W.; Smith, J. K.; Spangler, J. E.; Zhu, H.; Zhu, J.; Baran, P. S. Strain-Release Heteroatom Functionalization: Development, Scope, and Stereospecificity. J. Am. Chem. Soc. 2017, 139, 3209-3226.

(14) Levterov, V. V.; Michurin, O.; Borysko, P. O.; Zozulya, S.; Sadkova, I. V.; Tolmachev, A. A.; Mykhailiuk, P. K. Photochemical In-Flow Synthesis of 2,4-Methanopyrrolidines: Pyrrolidine Analogues with Improved Water Solubility and Reduced Lipophilicity. J. Org. Chem. 2018, 83, 14350-14361.

(15) Pirrung, M. C. Total Synthesis of 2,4-Methanaproline. Tetrahedron Letters 1980, 21, 4577-4578.

(16) Hughes, P.; Martin, M.; Clardy, J. Synthesis of 2,4-Methanoproline. Tetrahedron Letters 1980, 21, 4579-4580.

(17) Stevens, C.; De Kimpe, N. A New Entry into 2-Azabicyclo[2.1.1]Hexanes via 3-(Chloromethyl)Cyclobutanone. J. Org. Chem. 1996, 61, 2174-2178.

(18) Liao, H.; Li, A.; Chen, X.; Liang, K.; Shen, Y.; Liang, Q.; Xu, K.; Shore, D.; Villemure, E.; Siu, M.; Huestis, M. Preparation of 2-Azabicyclo[2.1.1]Hexane Hydrochloride. Synlett 2016, 27 (15), 2251-2253.

(19) Krow, G. R.; Herzon, S. B.; Lin, G.; Qiu, F.; Sonnet, P. E. Complex-Induced Proximity Effects. Temperature-Dependent Regiochemical Diversity in Lithiation-Electrophilic Substitution Reactions of N-BOC-2-Azabicyclo[2.1.1]Hexane. 2,4- and 3,5Methanoprolines. Org. Lett. 2002, 4, 3151-3154.

(20) Krow, G. R.; Shoulders, M. D.; Edupuganti, R.; Gandla, D.; Yu, F.; Sonnet, P. E.; Sender, M.; Choudhary, A.; DeBrosse, C.; Ross, C. W.; Carroll, P.; Raines, R. T. Synthesis of 5-Fluoroand 5-Hydroxymethanoprolines via Lithiation of N-BOCMethanopyrrolidines. Constrained $\mathrm{C} \gamma$-Exo and $\mathrm{C} \gamma$-Endo Flp and Hyp Conformer Mimics. J. Org. Chem. 2012, 77, 53315344.

(21) Krow, G. R.; Gandla, D.; Cannon, K. C.; Ross, C. W.; Carroll, P. J. C1-Substituted N-Tert-Butoxycarbonyl-5-Syn-Tert-Butyldimethylsilyloxymethyl-2-Azabicyclo[2.1.1]Hexanes as Conformationally Constrained $\beta$-Amino Acid Precursors. Heterocyclic Commun. 2016, 22, 319-328

(22) Wipf, P.; Fang, Z.; Ferrié, L.; Ueda, M.; Walczak, M. A. A.; Yan, Y.; Yang, M. Cycloadditions in Heterocycle and Alkaloid Synthesis. Pure Appl. Chem. 2013, 85, 1079-1087.

(23) Walczak, M. A. A.; Krainz, T.; Wipf, P. Ring-Strain-Enabled Reaction Discovery: New Heterocycles from Bicyclo[1.1.0]Butanes. Acc. Chem. Res. 2015, 48, 1149-1158.

(24) Fawcett, A.; Biberger, T.; Aggarwal, V. K. Carbopalladation of $\mathrm{C}-\mathrm{C} \sigma$-Bonds Enabled by Strained Boronate Complexes. $\mathrm{Na}$ ture Chem. 2019, 11 (2), 117-122.

(25) Fawcett, A.; Murtaza, A.; Gregson, C. H. U.; Aggarwal, V. K. Strain-Release-Driven Homologation of Boronic Esters: Application to the Modular Synthesis of Azetidines. J. Am. Chem. Soc. 2019, 141, 4573-4578.

(26) Silvi, M.; Aggarwal, V. K. Radical Addition to Strained $\sigma$ Bonds Enables the Stereocontrolled Synthesis of Cyclobutyl Boronic Esters. J. Am. Chem. Soc. 2019, 141, 9511-9515.

(27) Schwartz, B. D.; Zhang, M. Y.; Attard, R. H.; Gardiner, M. G.; Malins, L. R. Structurally Diverse Acyl Bicyclobutanes: Valuable Strained Electrophiles. Chem. Eur. J. 2020, 26, 28082812.
(28) Ociepa, M.; Wierzba, A. J.; Turkowska, J.; Gryko, D. PolarityReversal Strategy for the Functionalization of Electrophilic Strained Molecules via Light-Driven Cobalt Catalysis. J. Am. Chem. Soc. 2020, 142, 5355-5361.

(29) Carson, C. A.; Kerr, M. A. Diastereoselective Synthesis of Pyrrolidines via the $\mathrm{Yb}(\mathrm{OTf})_{3}$ Catalyzed Three-Component Reaction of Aldehydes, Amines, and 1,1-Cyclopropanediesters. $J$. Org. Chem. 2005, 70, 8242-8244.

(30) Schneider, T. F.; Kaschel, J.; Werz, D. B. A New Golden Age for Donor-Acceptor Cyclopropanes. Angew. Chem. Int. Ed. 2014, 53, 5504-5523.

(31) Singh, P.; Varshnaya, R. K.; Dey, R.; Banerjee, P. Donor-Acceptor Cyclopropanes as an Expedient Building Block Towards the Construction of Nitrogen-Containing Molecules: An Update. Adv. Synth. Catal. 2020, 362, 1447-1484.

(32) Lee-Ruff, E.; Mladenova, G. Enantiomerically Pure Cyclobutane Derivatives and Their Use in Organic Synthesis. Chem. Rev. 2003, 103, 1449-1484.

(33) Li, J.; Gao, K.; Bian, M.; Ding, H. Recent Advances in the Total Synthesis of Cyclobutane-Containing Natural Products. Org. Chem. Front. 2019, 7, 136-154.

(34) Goetzke, F. W.; Hell, A. M. L.; van Dijk, L.; Fletcher, S. P. A Catalytic Asymmetric Cross-Coupling Approach to the Synthesis of Cyclobutanes. Nature Chem. 2021, DOI: doi.org/10.1038/s41557-021-00725-y.

(35) Nicolaou, K. C.; Vourloumis, D.; Totokotsopoulos, S.; Papakyriakou, A.; Karsunky, H.; Fernando, H.; Gavrilyuk, J.; Webb, D.; Stepan, A. F. Synthesis and Biopharmaceutical Evaluation of Imatinib Analogues Featuring Unusual Structural Motifs. ChemMedChem 2016, 11, 31-37.

(36) Lim, J. J.; Leitch, D. C. Lewis Acid-Catalyzed Addition of Benzophenone Imine to Epoxides Enables the Selective Synthesis and Derivatization of Primary 1,2-Amino Alcohols. Org. Process Res. Dev. 2018, 22, 641-649.

(37) Allen, C. L.; Leitch, D. C.; Anson, M. S.; Zajac, M. A. The Power and Accessibility of High-Throughput Methods for Catalysis Research. Nature Catal. 2019, 2, 2-4.

(38) Laturski, A.; Bentley, J.; Gaffen, J.; Caputo, C.; Baumgartner, T. Probing the Impact of Solvent on Lewis Acid Catalysis via Fluorescent Lewis Adducts. ChemRxiv 2021. DOI: 10.33774/chemrxiv-2021-lrbts-v2.

(39) See Supporting Information for More Details.

(40) Swindell, C. S.; Patel, B. P.; DeSolms, S. J.; Springer, J. P. A Route for the Construction of the Taxane BC Substructure. $J$. Org. Chem. 1987, 52, 2346-2355.

(41) Elliott, L. D.; Booker-Milburn, K. I. Photochemically Produced Aminocyclobutanes as Masked Dienes in Thermal Electrocyclic Cascade Reactions. Org. Lett. 2019, 21, 1463-1466.

(42) Elliott, L. D.; Booker-Milburn, K. I.; Lennox, A. J. J. DaisyChaining Photo- and Thermal Chemistry: Multistep Continuous Flow Synthesis of Visible-Light-Mediated Photochemistry with a High-Temperature Cascade Reaction. Org. Process Res. Dev. 2021, 25, 1943-1949.

(43) Chen, J.; Goforth, S. K.; McKeown, B. A.; Gunnoe, T. B. Brønsted Acid-Catalysed Intramolecular Hydroamination of Unactivated Alkenes: Metal Triflates as an in Situ Source of Triflic Acid. Dalton Trans. 2017, 46, 2884-2891.

(44) Blanchard, E. P.; Cairncross, A. Bicyclo[1.1.0]Butane Chemistry. I. The Synthesis and Reactions of 3-Methylbicyclo[1.1.0]Butanecarbonitriles. J. Am. Chem. Soc. 1966, 88, 487-495.

(45) Mlostoń, G.; Heimgartner, H. The First Ring-Enlargement of a 1-Azabicyclo[1.1.0]Butane to a 1-Azabicyclo[2.1.1]Hexane. Helv. Chim. Acta 2006, 89, 442-449. 